\title{
Evaluation of the Effectiveness of Destructive Effects on Laser Guidance Systems of High-Precision Weapons
}

\author{
Alexander A. Dontsov, Victor V. Kalachev, \\ Yuriy L. Koziratsky and Evgeniy A. Levshin* \\ Military Educational and Scientific Center of Air Forces \\ "Air Force Academy named after N.E. Zhukovsky \\ and Yu.A. Gagarin" \\ Voronezh, Russian Federation
}

Received 20.07.2020, received in revised form 27.08.2020, accepted 15.09.2020

Abstract. The article presents the results of theoretical and experimental studies of destructive effects on the main channels of various types of semi-active laser homing heads of high-precision ammunition. Recommendations concerning characteristics of promising intended interference were confirmed experimentally. They make it possible to determine new methods of influence on laser guidance systems for high-precision ammunition and to expand the capabilities of electronic warfare devices when protecting stationary objects.

Keywords: laser homing head, high-precision ammunition, intended optical interference, electronic protection, stationary object.

Citation: Dontsov A.A., Kalachev V.V., Koziratsky Yu.L., Levshin E.A. Evaluation of the effectiveness of destructive effects on laser guidance systems of high-precision weapons, J. Sib. Fed. Univ. Eng. \& Technol., 2020, 13(7), 855-870. DOI: 10.17516/1999494X-0271

(C) Siberian Federal University. All rights reserved

This work is licensed under a Creative Commons Attribution-Non Commercial 4.0 International License (CC BY-NC 4.0).

* Corresponding author E-mail address: eugeny-vrn@mail.ru 


\title{
Оценка эффективности деструктивных воздействий на лазерные системы наведения высокоточного оружия
}

\author{
А.А. Донцов, В.В. Калачев, \\ Ю.Л. Козирацкий, Е.А. Левшин \\ Военный учебно-научный цуентр Военно-воздушных сил \\ “Военно-воздушная академия имени Н.Е. Жуковского и Ю.А. Гагарина" \\ Российская Федерации, Воронеж
}

Аннотациия. Приведены результаты теоретических и экспериментальных исследований деструктивных воздействий на основные каналы различных типов полуактивных лазерных головок самонаведения высокоточных боеприпасов. Экспериментально подтвержденные рекомендации по характеристикам перспективных преднамеренных помех позволяют определить новые способы воздействия на лазерные системы наведения высокоточных боеприпасов и расширить возможности средств радиоэлектронной борьбы при защите стационарных объектов.

Ключевые слова: лазерная головка самонаведения, высокоточный боеприпас, преднамеренная оптическая помеха, радиоэлектронная защита, стационарный объект.

Цитирование: Донцов, А.А. Оценка эффективности деструктивных воздействий на лазерные системы наведения высокоточного оружия / А.А. Донцов, В.В. Калачев, Ю.Л. Козирацкий, Е.А. Левшин // Журн. Сиб. федер. ун-та. Техника и технологии, 2020. 13(7). С. 855-870. DOI: 10.17516/1999-494X-0271

\section{Введение}

Лазерные системы наведения высокоточного оружия (ВТО) в настоящее время и на ближайшую перспективу остаются одними из наиболее эффективных средств поражения наземных (надводных) целей [1] и по многообразию типов поражаемых целей обладают значительной универсальностью. По некоторым оценкам, не менее 40 \% существующего арсенала ВТО оснащено полуактивными лазерными головками самонаведения (ЛГСН). Сообщается, что до настоящего времени произведено более 200 тысяч единиц только управляемых авиационных бомб типа GBU с ЛГСН, из которых более 40 тысяч единиц применены в локальных конфликтах последнего времени [2].

Одним из основных способов борьбы с этими высокоточными боеприпасами (ВТБ) является радиоэлектронная защита (РЭЗ) своих войск и объектов путем снижения эффективности функционирования ЛГСН преднамеренными оптическими помехами. Применение этих помех в военной сфере представляет одну из форм радиоэлектронной борьбы (РЭБ) [3].

\section{Анализ существующих решений}

В настоящее время с использованием существующей техники РЭБ возможно обеспечить защиту только особо важных малоразмерных стационарных объектов. При этом не решаются задачи РЭЗ масштабных (пространственно-протяженных, расположенных на больших площадях и пространственно-распределенных, расположенных в непосредственной близости друг от друга) объектов, которые достаточно широко представлены в номенклатуре стационарных объектов, подлежащих защите от ВТБ. 
Использование традиционных способов РЭЗ [4] масштабных военных и гражданских стационарных объектов может повлечь за собой перенацеливание ВТБ на соседние элементы или другие объекты, что не только не снижает степень нанесенного ущерба, но в ряде случаев может и увеличить его. Кроме того, важность сохранения функциональной целостности такого рода объектов определяет необходимость обеспечения высокой эффективности РЭЗ от поражения ВТБ особо важных его элементов [5]. Это требование может быть достигнуто при реализации способа РЭЗ стационарного объекта от ВТБ на основе контроля эффективности деструктивного воздействия преднамеренных оптических помех на головки самонаведения [6].

Цель работы - исследование эффективности деструктивных воздействий в виде маскирующих, имитирующих и возмущающих помех на основные каналы ЛГСН.

\section{Исследование воздействия маскирующих помех}

Повышение защищенности объектов от ВТБ с ЛГСН может быть обеспечено применением красок, покрытий, маскирующих накидок, снижающих показатели отражения защищаемым объектом зондирующего излучения лазерного дальномера-целеуказателя (ЛДЦУ) противника. Создание покрытий, снижающих коэффициенты отражения лазерного излучения до уровня, препятствующего эффективному применению ВТБ с ЛГСН во всем диапазоне дальностей его возможного применения, является достаточно сложной технической задачей. Однако вполне реально обеспечить уменьшение дальности эффективного применения таких ВТБ и, следовательно, повысить эффективность защиты маскируемого объекта.

Широко распространенный способ создания маскирующих помех против ЛГСН - постановка на линии визирования ВТБ-цели аэрозольной завесы (А3) [7]. При совмещенном подсвете цели, когда ЛДЦУ и пусковая установка боеприпаса с ЛГСН находятся в одной и той же точке пространства, аэрозольные облака нарушают визуальный контакт носителя с целью, то есть исключают сопровождение цели, а значит, и точное удержание лазерного луча на ней. В этом случае эффективность маскирующих помех при подавлении ВТБ с ЛГСН обусловлена, в первую очередь, эффективным подавлением телевизионных (ТВ) и тепловизионных (ТПВ) координаторов бортовых прицельных систем носителей, обеспечивающих наведение луча ЛДЦУ на цель.

При разнесенном подсвете цели, когда подсвет и пуск боеприпаса с ЛГСН могут выполняться с разных носителей или из разнесенных точек пространства, возможны ситуации, когда аэрозольная завеса перекрывает только линию визирования «ЛДЦУ-цель», но не линию визирования «ЛГСН-цель». Эффективность помехи в этом случае будет определяться успешным перенацеливанием ЛГСН с ослабленного лазерного пятна на цели сформированного приходящим сквозь аэрозольную завесу излучением ЛДЦУ, на лазерное пятно, образованное излучением ЛДЦУ, рассеянного аэрозольной завесой назад, то есть в направлении на ЛГСН. При этом лазерное пятно на завесе можно трактовать как своеобразную лазерную ложную цель (ЛЛЦ), спектрально-временные характеристики которой автоматически воспроизводят спектрально-временные характеристики излучения ЛДЦУ, что обеспечивает преодоление сигналом ЛЛЦ устройств спектрально-временной селекции ЛГСН.

Для диффузно-отражающей цели отношение на апертуре ЛГСН мощности (энергии) излучения, рассеянного завесой, к мощности отраженного от цели излучения (отношение помехасигнал) определяется выражением

$$
-857-
$$




$$
q=\frac{\pi f(\theta) D_{s}^{2}}{\rho_{s} \tau_{a} D_{a}^{2}},
$$

где $f(\theta)$ - нормированная (соответствующая единичной мощности подсвета) индикатриса рассеяния завесой назад излучения ЛДЦУ [8], характеризующая силу излучения ЛЛЦ, образовавшейся на АЗ; $\theta$ - угол между направлениями на ЛДЦУ и ЛГСН; $D_{s}$ - дальность от ЛГСН до цели; $D_{a}$ - дальность от ЛГСН до аэрозольной завесы; $\rho_{s}-$ коэффициент отражения цели; $\tau_{a}-$ коэффициент пропускания А3.

Для определения необходимых исходных данных по временным и энергетическим параметрам преднамеренных оптических помех были выполнены экспериментальные исследования по оценке эффективности деструктивных воздействий в виде маскирующих, имитирующих и возмущающих помех на основные каналы ЛГСН, в том числе в режиме вскрытия кодовой последовательности излучения подсвета.

Эксперименты проводили в стендовых условиях на лабораторной установке [9], в состав которой входят: ЛГСН гиростабилизированного типа с малым полем зрения и захватом цели на борту летательного аппарата (ЛГСН-Г), ЛГСН флюгерного типа с большим полем зрения и возможностью захвата цели на траектории полета ВТБ (ЛГСН-Ф); сервисная аппаратура запуска и задания режимов работы ЛГСН; линза, формирующая на фотоприемном устройстве (ФПУ) ЛГСН изображение точечного источника; имитатор цели (полупроводниковый лазер, формирующий излучение на длине волны 1,06 мкм); генератор кодовой последовательности, обеспечивается кодированный подсвет цели и высокую помехозащищенность ЛГСН; имитатор помехи; импульсный генератор, задающий частоту следования импульсов излучения имитатора помехи; осциллограф и ПЭВМ для визуализации и регистрации процессов измерений. Схема расположения аппаратуры при проведении исследований представлена на рис. 1 .

На рис. 1 обозначено: 1 - ЛГСН-Г (ЛГСН-Ф) с полем зрения $2 \alpha ; 2$ - сервисная аппаратура для ЛГСН; 3 - линза с фокусным расстоянием $f ; 4$ - полупроводниковый лазер (имитатор цели); 5 - полупроводниковый лазер (имитатор помехи); 6 - импульсный генератор; 7 - генератор кодовой последовательности; 8 - осциллограф; 9 - ПЭВМ. В качестве имитатора помехи использовали полупроводниковый лазер, формирующий аналогично имитатору цели излучение на длине волны 1,06 мкм. Излучения имитаторов цели и помехи направлялись через линзу

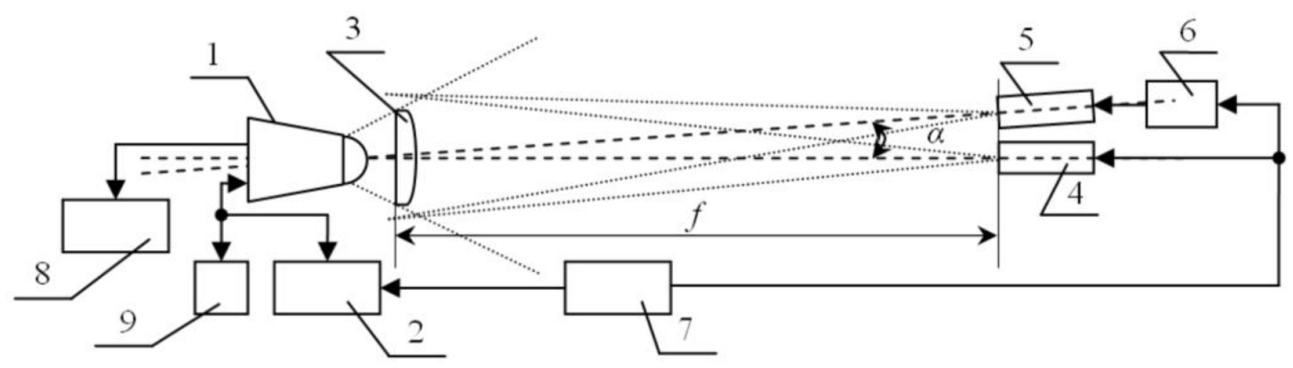

Рис. 1. Схема проведения исследований

Fig. 1. Scheme of research 
в сторону оптической системы ЛГСН. С использованием аттестованного измерителя лазерной энергии, обладающего чувствительностью до $10^{-8} \mathrm{BT} / \mathrm{cm}^{2}$, регистрировали плотность мощности принимаемого излучения на входной апертуре ЛГСН. При определении временных и энергетических параметров преднамеренных оптических помех, требуемых для эффективного деструктивного воздействия на ЛГСН, импульсным генератором варьировались временные положения, частота повторения и амплитуда помеховых импульсов. Отношение помеха/сигнал определяет энергетику, которая необходима для устойчивого увода и перенацеливания ЛГСН с имитатора цели на имитатор помехи за счет деструктивного воздействия. Методом статистических испытаний определяется вероятность увода ЛГСН $P$ от заданного отношения помеха/ сигнал $q$. Первоначально экспериментальные исследования проводили для ЛГСН-Г с последующей заменой на ЛГСН-Ф. Полученные результаты исследований представлены на рис. 2, где обозначено: 1 - для ЛГСН-Г; 2 - для ЛГСН-Ф.

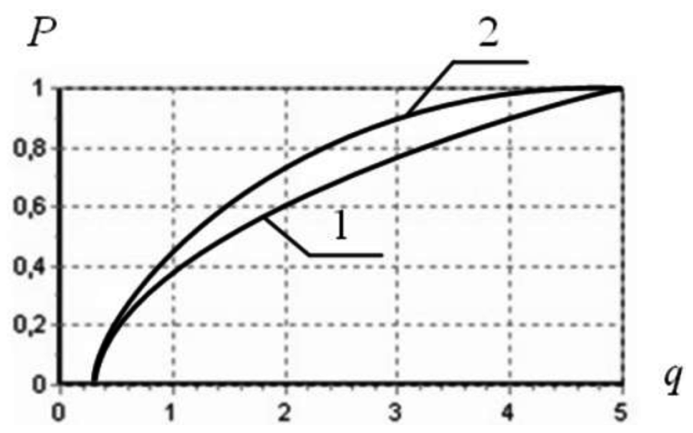

Рис. 2. Зависимость вероятности увода ЛГСН $P$ от отношения помеха-сигнал $q$

Fig. 2. Dependence of the probability of LGSN withdrawal $P$ on the interference-signal ratio $q$

Анализ результатов экспериментальных исследований позволяет сделать вывод, что для обеспечения устойчивого перенацеливания ЛГСН на АЗ необходимо выполнение неравенства $q \geq 3 \ldots 5$.

\section{Исследование воздействия имитирующих помех}

Перспективным способом борьбы с управляемыми боеприпасами, оснащенными ЛГСН, явлются деструктивные воздействия на основе имитирующих помех за счет постановки ЛЛЦ [7]. Такая помеха может быть создана путем подсвета излучением помехового лазера участка местности, аэрозольного облака или специальной мишени, расположенных вблизи защищаемого объекта.

При создании ЛЛЦ путем подсвета излучением помехового лазера аэрозольной завесы $D_{s} \approx D_{a}$ выражение (1) принимает вид

$$
q=\frac{P_{a} \pi f(\theta)}{P_{s} \rho_{s}},
$$

где $P_{a}, P_{s}$ - мощность (энергия) импульсов помехового лазера и ЛДЦУ соответственно.

$$
-859-
$$


При создании ЛЛЦ необходимо обеспечить преодоление сигналом ЛЛЦ интерференционного фильтра и устройств временной селекции ЛГСН, то есть обеспечить с минимальной задержкой повторение помеховыми импульсами зондирующих цель импульсов ЛДЦУ. Последнее может быть выполнено путем применения в качестве помехового излучателя лазерного усилителя-ретранслятора, а также путем декодирования и последующего воспроизводства используемой ЛДЦУ кодовой импульсной последовательности. Наиболее эффективным и энергетически выгодным (мощность излучения помехового лазера сопоставима с мощностью излучения ЛДЦУ) способом постановки ЛЛЦ является способ на основе формирования деструктивного воздействия помехового излучения в режиме создания имитирующих несинхронных помех, для которых не требуется информации о параметрах (кодовой импульсной последовательности) излучения ЛДЦУ.

Как показали подтвержденные экспериментом исследования [7], эффект преодоления сигналом ЛЛЦ временной селекции ЛГСН второго поколения, обладающей относительно большой длительностью временного строба, будет достигаться, если частоту помехи выбирать в соответствии с выражением

$$
f_{a}=\frac{f_{s}}{1-\Delta T_{s} f_{s}}
$$

где $f_{a}, f_{s}$ - частота повторения импульсов помехового лазера и ЛДЦУ соответственно; $\Delta T_{s}-$ длительность временного строба ЛГСН.

Результаты расчета показывают, что при $\Delta T_{s}=5$ мс и $f_{s}=10$ Гц частота повторения импульсов помехового лазера для устойчивого увода ЛГСН второго поколения на ЛЛЦ будет равна $f_{a}=10,5$ Гц.

Однако повышение помехозащищенности современных и перспективных ЛГСН, в том числе за счет применения кодированного излучения подсвета и уменьшения длительности временного строба, сильно осложняет задачу преодоления схем временной селекции ЛГСН. Применение имитирующей несинхронной помехи с частотой повторения импульсов помехового лазера, незначительно отличающейся от частоты повторения импульсов ЛДЦУ для ЛГСН с узким временным стробом, нецелесообразно в виду ее низкой эффективности.

Особенность схем временной селекции помехозащищенных ЛГСН - временное стробирование приемного тракта. В настоящее время известны ЛГСН с временными стробами анализа $70 . .100$ мкс [1]. Длительность такого строба выбирают из условия обеспечения приема отраженного сигнала от цели во всем диапазоне дальностей применения ВТБ и определяют по формуле

$$
\Delta T_{1}=\frac{D}{c},
$$

где $D$ - дальность применения ВТБ; $c$ - скорость света.

Расчеты показывают, что при длительности временного строба анализа ЛГСН $\Delta T_{1}=70$ мкс максимальная дальность применения ВТБ не должна быть более 21 км.

При этом импульс строба начинает формироваться с задержкой относительно прогнозируемого времени приема отраженного импульса ЛДЦУ на время [10]:

$$
\Delta T_{2}=\frac{3 \sqrt{2} \delta c+2 V}{f_{s} c},
$$


где $\delta$ - относительная стабильность частоты повторения импульсов ЛДЦУ и работы устройства формирования временного строба в ЛГСН; $V$ - скорость сближения ВТБ с целью.

Величина задержки в перспективных ЛГСН высокоточных боеприпасов будет определяться нестабильностью частоты повторения импульсов излучения ЛДЦУ, и в соответствии с условиями $f_{s}=10$ Гц, $V=500 \mathrm{~m} / \mathrm{c}, \delta=(0,4 \ldots 1,1) \cdot 10^{-7}$ ее минимальное значение может лежать в пределах $2 \ldots 5$ мкс.

Таким образом, длительность временного строба ЛГСН равна $\Delta T=\Delta T_{I}+\Delta T_{2}$, которая, в первую очередь, определяется максимальной дальностью применения ВТБ. Результаты влияния частоты повторения импульсов излучения помехового лазера $f_{a}$ на вероятность увода ЛГСН $P$ с имитатора цели на имитатор помехи при отношении помеха/сигнал $q=3$ и длительности временного строба ЛГСН $\Delta T=75$ мкс приведены на рис. 3, где обозначено: 1 - для ЛГСН-Г; 2 - для ЛГСН-Ф.

Сравнение результатов эксперимента при деструктивном воздействии имитирующей помехи на различные типы ЛГСН, показывает схожий вид зависимостей вероятности увода ЛГСН-Г и ЛГСН-Ф от частоты повторения импульсов излучения помехового лазера с незначительной погрешностью $\pm 5 \ldots 10 \%$.

Проведенные исследования эффективности деструктивного воздействия на основе несинхронной имитирующей помехи с большой частотой повторения импульсов излучения демонстрируют, что имитирующая помеха с частотой повторения импульсов $f_{a}=0,75$ кГц обеспечивает вероятность увода ЛГСН более 0,9 при отношении помеха/сигнал не менее 3 (рис. 3).

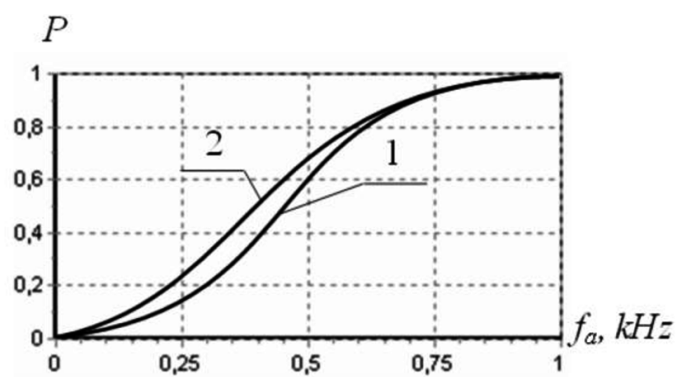

Рис. 3. Зависимость вероятности увода ЛГСН от частоты излучения помехи

Fig. 3. Dependence of the probability of LGSN withdrawal on the frequency of interference radiation

Следует отметить, что увеличение плотности мощности излучения помехи на входной апертуре ЛГСН, то есть отношения помеха/сигнал $q>3$, не приводит к существенному снижению требований к частоте повторения импульсов излучения несинхронной имитирующей помехи в связи с относительно узким временным стробом современных ЛГСН.

\section{Исследование воздействия возмущающих помех}

В проблематике оптико-электронного подавления (ОЭП) в последнее время заметное место отводится вопросам групповой защиты, то есть защиты помехами из одной точки группы объектов, размещенных в различных точках, некоторой области пространства [11]. Возможно- 
сти групповой защиты в общем случае ограничиваются тем, что помехи, создаваемые из одной точки пространства, могут не попадать в поле зрения ЛГСН ВТБ, атакующего другой объект группы.

Создание эффективных помех с направлений вне поля зрения ЛГСН (с боковых направлений) требует увеличения мощности источника помехового излучения. Наряду с маскирующими и имитирующими для подавления ЛГСН могут использоваться также возмущающие помехи, действие которых связано с засветкой (ослеплением) ФПУ ЛГСН [7]. Возмущающая (засветочная) помеха создается импульсным или непрерывным лазерным помеховым излучением достаточной мощности, лежащим в полосе пропускания интерференционного фильтра. При этом согласование временной последовательности помеховых импульсов с кодовой последовательностью импульсов ЛДЦУ, то есть преодоление устройств временной селекции ЛГСН, не требуется.

Для оценки эффективности деструктивных воздействий с боковых направлений была дополнена лабораторная установка, представленная на рис. 1, промышленным твердотельным лазером, создающим мощное помеховое излучение, и фильтродержателем с цветными светофильтрами, варьирующими плотность мощности лазерного излучения. Схема расположения аппаратуры при проведении исследований помех с боковых направлений представлена на рис. 4 .

На рис. 4 обозначено: 1 - ЛГСН-Г (ЛГСН-Ф); 2 - сервисная аппаратура для ЛГСН; 3 - линза с фокусным расстоянием $f ; 4$ - полупроводниковый лазер (имитатор цели); 5 - твердотельный лазер (имитатор помехи); 6 - фильтродержатель; 7 - генератор кодовой последовательности; 8 - осциллограф; 9 - ПЭВМ.

Излучение помехового лазера направляется в сторону ФПУ ЛГСН, а его плотность мощности регистрируется аттестованным измерителем лазерной энергии. Путем смещения опти-

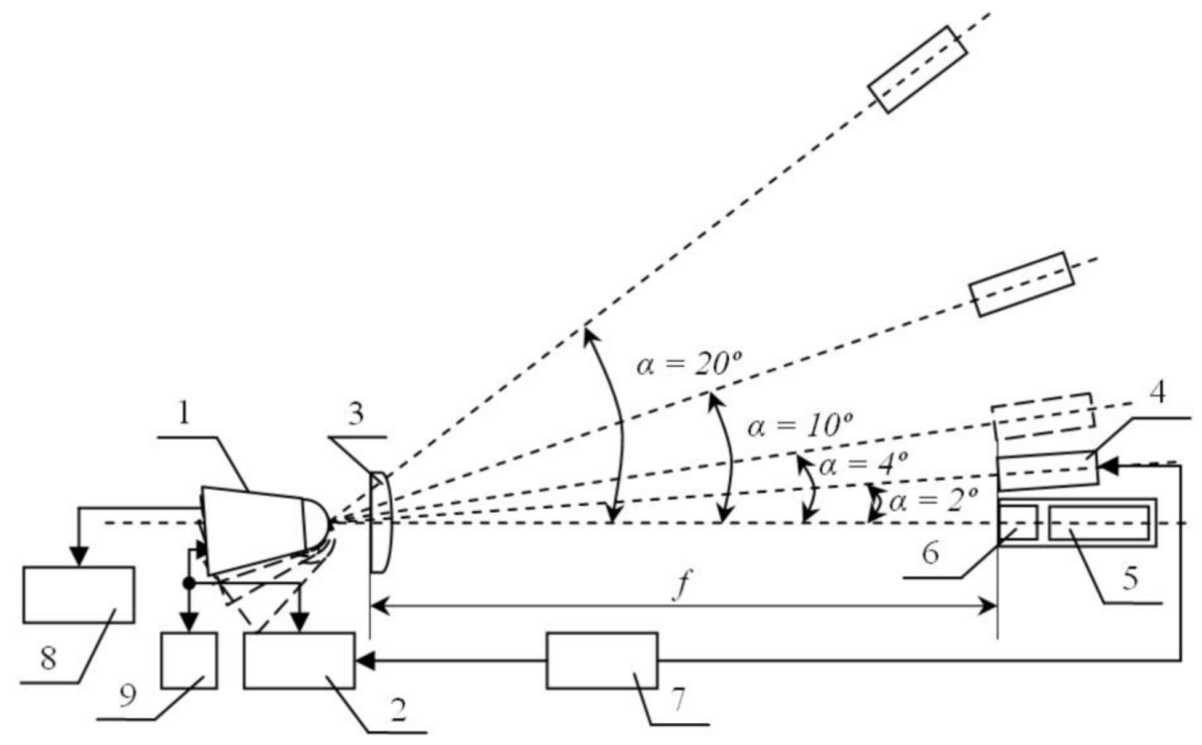

Рис. 4. Схема проведения исследований помех с боковых направлений

Fig. 4. Scheme of research of interference from lateral directions 
ческой оси ЛГСН добиваются, чтобы угол рассогласования по одной из координат находился в нуле, а по другой координате был максимальным в поле зрения ЛГСН. При увеличении мощности лазерного излучения за счет подбора цветных светофильтров происходит уменьшение напряжения сигнала рассогласования ЛГСН, что свидетельствует о начале засветки ФПУ. Дальнейшее повышение мощности излучения помехового лазера приводит к тому, что напряжение сигнала рассогласования ЛГСН не изменяется или принимает хаотичное значение.

Результаты исследований показывают, что создание возмущающей (засветочной) помехи оказывает воздействие на цепь автоматической регулировки усиления (АРУ) подавляемых ЛГСН [7]. Наличие во входных цепях ЛГСН петли АРУ по шумам, обеспечивающей формирование порогового уровня захвата цели, приводит к тому, что в результате воздействия достаточно мощного когерентного или некогерентного помехового сигнала, преодолевшего интерференционный фильтр, такая система АРУ вместо формирования порога захвата цели по средней мощности естественных (фоновых и внутренних) шумов будет формировать порог захвата по средней мощности проникающего помехового сигнала, наделенного квазислучайной шумовой модуляцией. При этом полезный сигнал в усилителе, охваченном петлей АРУ, окажется подавленным, а входные сигналы каналов ЛГСН становятся равными максимально возможным и при вычитании взаимно компенсируются, что приводит к пропаданию управляющих сигналов. В этом случае считалось, что помеха по характеру воздействия является возмущающей, и определялась необходимая плотность мощности лазерного помехового излучения (критериальный уровень) для эффективного подавления ЛГСН.

Основными факторами, определяющими возможность подавления ЛГСН с боковых направлений, могут быть:

дифракция принимаемого излучения на элементах приемной оптической системы;

рассеяние излучения атмосферой на трассе распространения;

рассеяние излучения на неоднородностях входной оптики;

многократное переотражение и рассеяние излучения конструктивными элементами ФПУ.

Зависимости плотности мощности помехового излучения на входной апертуре ЛГСН, приводящей к фоновой засветке ФПУ, от величины сигнала ЛДЦУ $E_{s}$ (при $f_{a}=10$ Гц, $\alpha=2^{\circ}$ ), частоты повторения импульсов помехового лазера $f_{a}$ (при $E_{s}=10^{-4} \mathrm{BT} / \mathrm{cm}^{2}$ и $\alpha=2^{\circ}$ ) и углового расстояния между целью и ЛЛЦ $\alpha$ (при $E_{s}=10^{-4} \mathrm{Bт} / \mathrm{cm}^{2}$ и $f_{a}=10$ Гц) приведены на рис. 5 , где: 1 - в поле зрении ЛГСН-Г; 2 - вне поля зрении ЛГСН-Г; 3 - в поле зрении ЛГСН-Ф.

Анализ графиков, представленных на рис. 5, позволяет сделать вывод о том, что воздействие мощного лазерного излучения на ЛГСН приводит к срыву сопровождения цели на время действия возмущающей помехи. Минимальная плотность мощности помехового излучения на входной апертуре ЛГСН, приводящая к фоновой засветке ФПУ и срыву режима захвата цели, зависит от уровня излучения ЛДЦУ $E_{s}$, частоты повторения импульсов помехового лазера $f_{a}$ и углового расстояния между целью и ЛЛЦ $\alpha$, и составляет:

$0,14 \ldots 0,28 \mathrm{BT} / \mathrm{cm}^{2}$ при величине сигнала ЛДЦУ $E_{s}=10^{-7} \ldots 10^{-4} \mathrm{BT} / \mathrm{cm}^{2}$;

$0,24 \ldots 1,60 \mathrm{BT} / \mathrm{cm}^{2}$ при частоте следования помехового сигнала $f_{a}=12,5 \ldots 2,5$ Гц;

$0,24 \ldots 2,00 \mathrm{BT} / \mathrm{cm}^{2}$ (для ЛГСН-Г) и $0,015 \ldots 0,80 \mathrm{Bт} / \mathrm{cm}^{2}$ (для ЛГСН-Ф) при угловом расстоянии между целью и ЛЛЦ $\alpha=2 \ldots 20$ град.

$$
-863-
$$




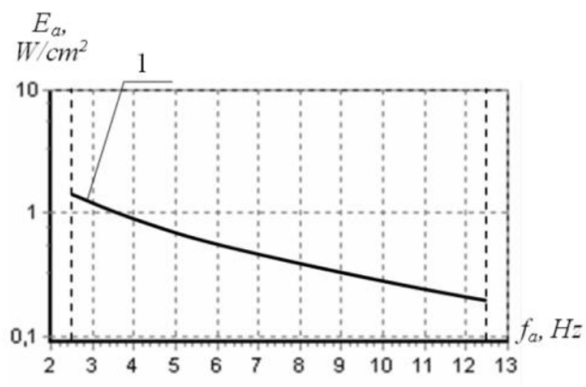

a)

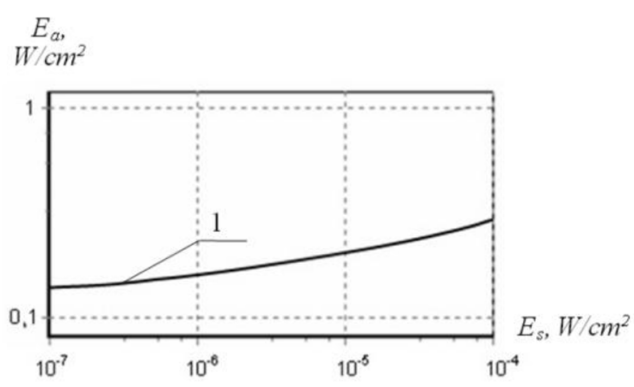

б)

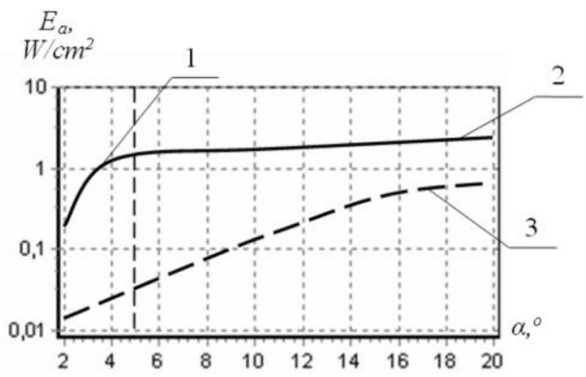

B)

Рис. 5. Зависимости плотности мощности помехового излучения от величин $E_{s}(\mathrm{a}), f_{a}$ (б), $\alpha$ (в)

Fig. 5. Dependences of the power density of interference radiation on the values of $E_{s}(\mathrm{a}), f_{a}$ (b), $\alpha$ (c)

Критериальные уровни деструктивных воздействий с боковых направлений для эффективного подавления ЛГСН не зависят от согласования временной последовательности помеховых импульсов с кодовой последовательностью импульсов ЛДЦУ. Снижение чувствительности, увеличение уровня шумов и искажение дискриминационной характеристики ФПУ ЛГСН являются факторами, которые необходимо использовать при создании лазерных средств ОЭП, реализующих возмущающую помеху. В этом случае для нарушения функционирования ЛГСН требуется обеспечить на чувствительных элементах ФПУ (кремниевых ріn-фотодиодов) плотность мощности помехового излучения на длине волны $\lambda=1,06$ мкм, равную $1 \ldots 2$ Вт/см 2 .

Другим видом возмущающих помех могут быть помехи, действующие по цепям регулирования положения рабочей точки фотоприемника и приводящие к насыщению каскадов усиления и перерывам поступления информации о цели в ЛГСН (прерывистые помехи) [7]. Вполне очевидно, что уровень облученности входной апертуры ЛГСН, приводящий к насыщению ФПУ, задается произведением пороговой чувствительности ЛГСН по входному сигналу на величину ее динамического диапазона. Для обеспечения надежного подавления ЛГСН этот уровень должен быть превышен помеховым сигналом в три и более раз, то есть составлять не менее $(0,5 \ldots 0,8) \cdot 10^{-2} \mathrm{~B} / \mathrm{cm}^{2}$. В ряде контуров самонаведения для исключения нежелательного маневрирования ВТБ в непосредственной близости цели при насыщении его приемного устройства контур самонаведения размыкается и ВТБ завершает процесс самонаведения в неуправляемом полете. Дальность, на которой это происходит, называется дальностью ослепления и может составлять десятки - первые сотни метров. При создании помехи, приводящей к насыщению ФПУ ЛГСН на больших дальностях и соответствующему увеличению дальности 
ослепления до сотен метров - первых километров, ВТБ с такой ЛГСН будет вынужден преодолевать значительную часть траектории наведения в неуправляемом полете.

Для создания прерывистой помехи следует обеспечить периодическую модуляцию по амплитуде поступающего на вход ЛГСН полезного сигнала не менее чем десятикратным перепадом амплитуды за период [7]. Периодическая амплитудная модуляция входного сигнала при создании прерывистой помехи может быть реализована с помощью активного лазерного излучателя либо пассивного лазерного управляемого световозвращателя, размещаемого на защищаемом объекте. Такой световозвращатель может быть построен в виде матрицы элементарных уголковых оптических отражателей или пакета оптоволоконных линий с собирающей линзой на их приемном конце и зеркальной поверхностью на другом конце [7], перед которыми установлен, например, механический прерыватель лучистого потока. Как нетрудно показать, площадь входной поверхности матрицы уголковых отражателей или собирающей линзы необходимо выбирать в соответствии с выражением

$$
S=\frac{v \gamma j \rho_{0} D^{2}}{\pi \rho_{s}}
$$

где $v$ - требуемое отношение $u_{\text {Imax }} / u_{\text {Imin }} ; \gamma, j$ - углы расходимости излучения ЛДЦУ и отраженного уголковым отражателем соответственно; $\rho_{0}, \rho_{s}-$ коэффициенты отражения матрицы уголковых отражателей и защищаемого объекта; $D$ - максимальная дальность подавления ЛГСН.

При типовых значениях $D=1$ км, $\gamma=10^{-6} \mathrm{cp}, j=10^{-4} \mathrm{cp}, \rho_{0}=0,9, \rho_{s}=0,2, v=10$ площадь входной поверхности управляемого отражателя $S=14 \mathrm{~cm}^{2}$, что не создает принципиальных трудностей для размещения такого устройства защиты на масштабных объектах.

Также световозвращатель может быть выполнен в виде специального пленочного материала (с мультизеркальной структурой отражения лазерного излучения) [12], обладающего рядом уникальных свойств, которые позволяют его рассматривать как пассивное средство создания помех схемам захвата ЛГСН.

Обычно команда на захват цели в ЛГСН формируется специальными логическими схемами лишь при наличии устойчивого приема полезного сигнала в течение интервала времени порядка $0,3 \ldots 1$ с. Наличие неустойчивого режима может исключить срабатывание таких схем, за счет чего может быть сорван захват цели в ЛГСН. При использовании кодированного излучения для подсвета цели описанная прерывистая помеха искажает принимаемую кодовую последовательность, что для некоторых схем декодирования может также исключить захват по коду полезного сигнала в ЛГСН.

Диэлектрические пленочные материалы с мультизеркальной структурой отражения излучения имеют сложный характер индикатрисы рассеяния. На рис. 6 показано изображение сечения индикатрисы рассеяния излучения образцом пленочного материала, который состоит из мультизеркальных трехгранных пирамид с размером элементарной ячейки 250 мкм и углом при вершине $60^{\circ}$, а также содержит центральный луч и шесть периферийных лучей, расположенных симметрично относительно центрального. Угол между центральным и периферийным лучами составляет примерно $40^{\circ}$.

Для оценки эффективности деструктивных воздействий на схему захвата ЛГСН была доработана лабораторная установка, изображенная на рис. 4 , за счет применения поворотного

$$
-865-
$$




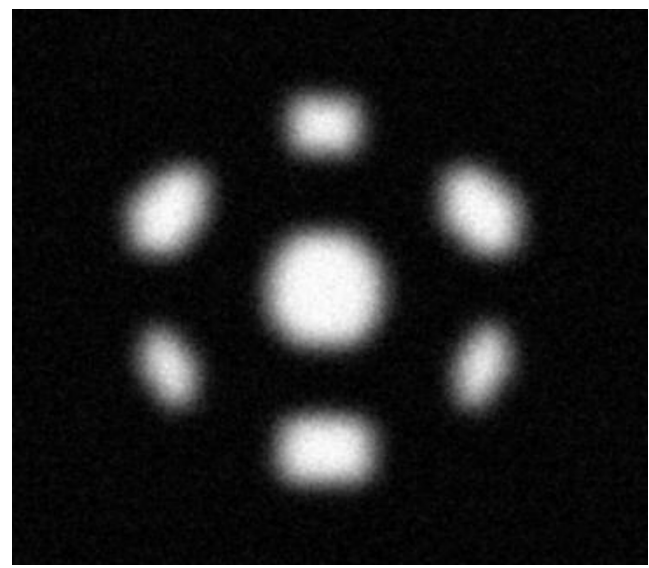

Рис. 6. Изображение сечения индикатрисы образца пленочного материала

Fig. 6. Image of a cross-section of the indicatrix of a sample of film materials

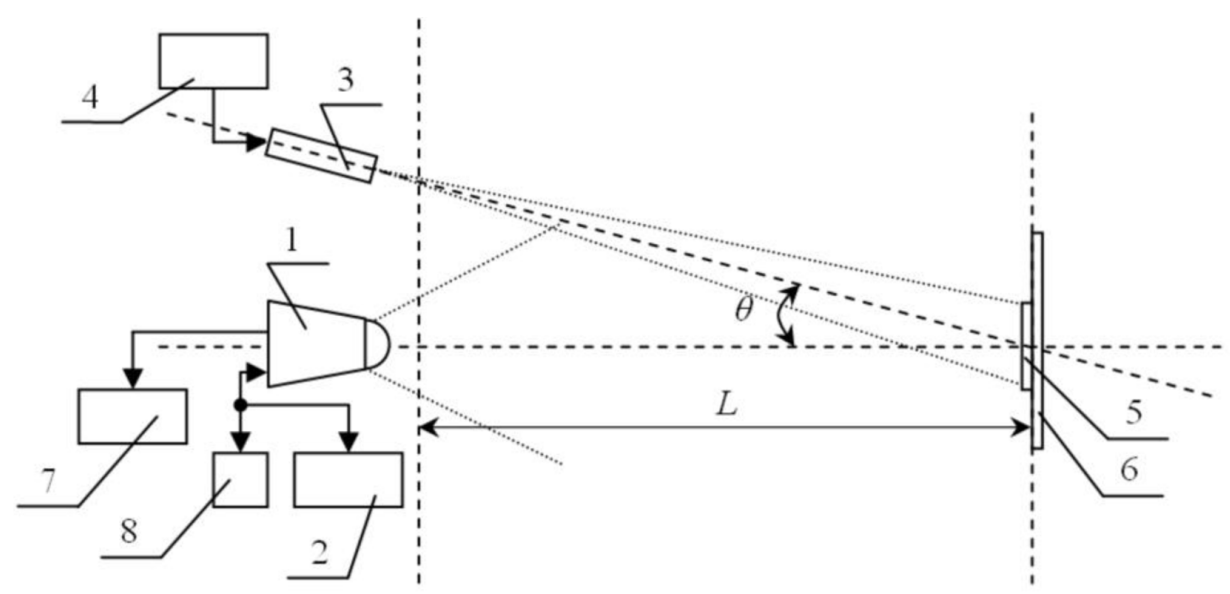

Рис. 7. Схема проведения исследований помех схемам захвата ЛГСН

Fig. 7. Scheme of research of interference to schemes of capture of LGSN

экрана диффузного типа, на который закрепляли отражающее пленочное покрытие. Схема расположения аппаратуры при проведении исследований помех схемам захвата ЛГСН представлена на рис. 7.

На рис. 7 обозначено: 1 - ЛГСН-Г (ЛГСН-Ф); 2 - сервисная аппаратура для ЛГСН; 3 твердотельный лазер (имитатор цели); 4 - сервисная аппаратура для лазера; 5 - пленочный материал; 6 - диффузный экран; 7 - осциллограф; 8 - ПЭВМ; $L$ - расстояние между ЛГСН (имитатором цели) и диффузным экраном; $\theta$ - угол между направлением на ЛДЦУ и ЛГСН.

В ходе эксперимента определяются отражательные характеристики имитатора цели (экрана диффузного типа) с отражающим пленочным покрытием и без него (коэффициенты диффузного отражения), а также вероятности срыва сопровождения цели ЛГСН-Г (ЛГСН-Ф).

Коэффициент диффузного отражения от пленочного покрытия $\rho_{p}$ вычисляют в соответствии с выражением: 


$$
\rho_{p}=\frac{\rho_{s} \cdot E_{p}}{E_{s}}
$$

где $\rho_{s}-$ коэффициент диффузного отражения от имитатора цели (диффузного экрана); $E_{s}, E_{p}-$ плотности мощности излучения на входной апертуре ЛГСН при измерении отраженного излучения ЛДЦУ от диффузного экрана и пленочного покрытия соответственно.

Результаты измерений плотности мощности излучения на входной апертуре ЛГСН от угла между направлением на ЛДЦУ и ЛГСН $\theta$ при различных отражательных характеристиках имитатора цели представлены на рис. 8, где обозначено: 1 - пленочный материал; 2 - диффузный экран.

Как видно из данных рис. 8, пленочный материал имеет отличную от диффузного экрана характеристиу отражения. Зеркальные составляющие имеют узконаправленный характер,

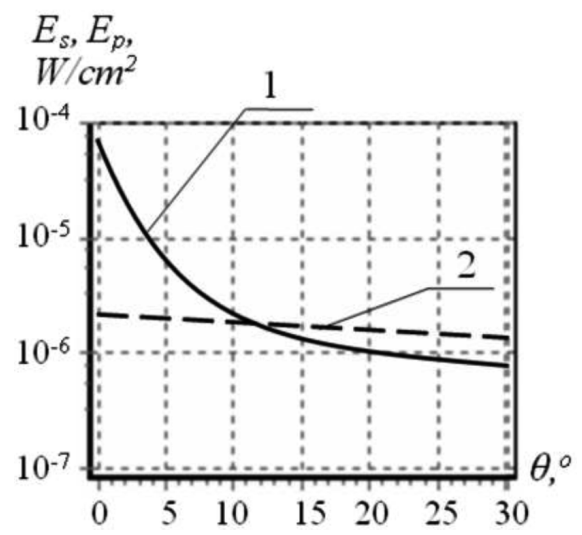

Рис. 8. Зависимости плотности мощности излучения от угла $\theta$ для различных целей

Fig. 8. Dependences of the power density of radiation on the angle $\theta$ for different targets

и создаваемая ими плотность мощности излучения на входной апертуре ЛГСН существенно превышает плотность мощности излучения от диффузного отражателя. В то же время диффузная составляющая излучения, отраженного от пленочного покрытия, лежит в пределах $\rho_{p}=0,08 \ldots 0,12$, что несколько (в $1,3 \ldots .2,0$ раза) ниже, чем у диффузного экрана $\rho_{s}=0,16$. Общий диапазон флуктуаций плотности мощности излучения на входной апертуре ЛГСН, обусловленных изменением взаимной ориентации поверхности диффузного экрана, ЛДЦУ и ЛГСН, для пленочного материала составляет более двух порядков (диапазон изменения плотности мощности излучения $\left.-(0,88 \ldots 80) \cdot 10^{-6} \mathrm{BT} / \mathrm{cm}^{2}\right)$, тогда как для диффузного экрана не превышает $1,5 \ldots 2$ раза $-(1,27 \ldots 2,78) \cdot 10^{-6} \mathrm{BT} / \mathrm{cm}^{2}$.

На рис. 9 представлены временные диаграммы выходных сигналов ЛГСН (1 - напряжение рассогласования по горизонтальной плоскости; 2 - напряжение рассогласования по вертикальной плоскости; 3 - команда «Захват»; 4 - напряжение схемы автоматической регулировки усиления) при периодическом изменении углового положения поверхности диффузного экрана с закрепленным на него пленочным материалом с частотой 1 Гц и амплитудой $\pm 15^{\circ} . .20^{\circ}$ относительно положения, при котором нормаль к поверхности диффузного экрана направлена

$$
-867-
$$




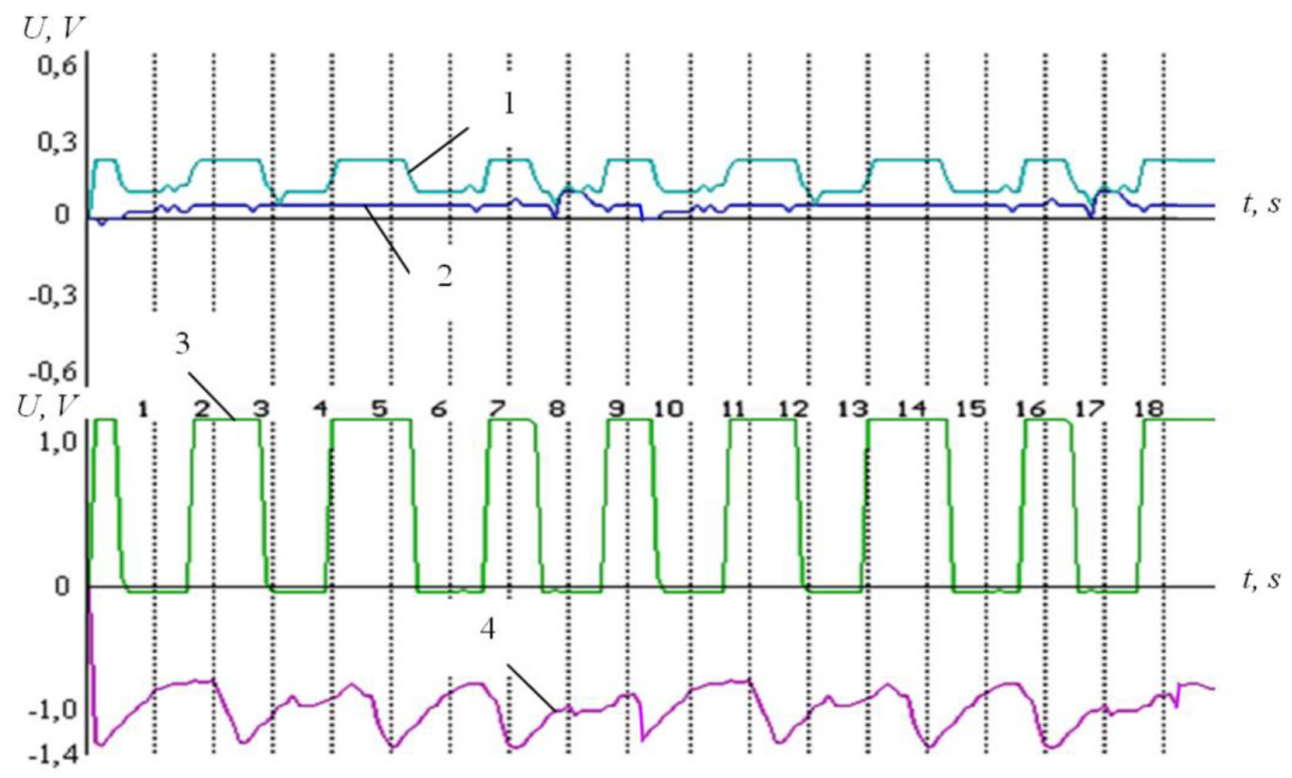

Рис. 9. Временные диаграммы выходных сигналов ЛГСН

Fig. 9. Timing diagrams of output signals of LGSN

на ЛГСН. Зависимости получены для случая совмещенного подсвета, когда угол между направлениями на ЛДЦУ и ЛГСН составляет $\theta \sim 3 \ldots 4^{\circ}$.

Оцениваемый показатель - вероятность срыва сопровождения цели ЛГСН - определяется как отношение времени отсутствия сигнала «Захват» к общему времени сопровождения (к длительности реализации). По результатам усреднения десяти реализаций, вероятности срыва сопровождения цели ЛГСН-Г и ЛГСН-Ф составляют 0,45 и 0,38 соответственно, что свидетельствует о схожести характера деструктивного воздействия на схемы захвата различных типов ЛГСН.

Результаты проведенных исследований подтверждают потенциальную эффективность применения световозвращателей (пленочных материалов) в качестве средств создания возмущающих (прерывистых) помех схемам захвата ЛГСН при защите объектов военного и гражданского назначения от ВТБ с лазерными системами прицеливания и наведения. Диэлектрические пленочные материалы с мультизеркальной структурой отражения излучения обеспечивают существенно более низкий уровень диффузной составляющей отраженного излучения на длине волны 1,06 мкм (в 1,3...2 раза ниже, чем у объекта со штатным покрытием - диффузным экраном), что, соответственно, ведет к снижению максимальной дальности применения ВТБ с ЛГСН. Кроме того, наличие слабой диффузной и мощных зеркальных составляющих порождает в пространстве существенно неоднородное и нестационарное распределение мощности излучения ЛДЦУ, отраженного от объекта защиты с закрепленным на него пленочным материалом, что приводит к нарушениям в работе ЛГСН и срыву сопровождения цели (команды «Захват»). 


\section{Заключение}

Преднамеренные оптические помехи в ряде случаев могут парадоксальным образом трансформировать достоинства современного и перспективного ВТБ в его недостатки. Так, с помощью деструктивного воздействия на основе маскирующих и имитирующих помех за счет постановки ЛЛЦ может быть обеспечено нацеливание ВТБ в точку, выбранную не нападающей, а защищающейся стороной, что невозможно обеспечить при защите от обычного неуправляемого оружия. Одним из перспективных направлений противодействия многоцелевым ВТБ с ЛГСН является создание возмущающих (засветочных, прерывистых) помех чувствительным элементам ФПУ и схемам захвата ЛГСН, приводящих к пропаданию управляющих сигналов в электронном тракте ЛГСН и размыканию цепи, соединяющей выходные сигналы головки самонаведения с контуром автопилота, тем самым обеспечивая срыв режима самонаведения управляемого боеприпаса. Эффективность деструктивных воздействий на ЛГСН предоставляет в ряде случаев стороне ОЭП новые способы воздействия на радиоэлектронные системы наведения ВТБ, расширяющие возможности средств радиоэлектронной борьбы при защите масштабных военных и гражданских стационарных объектов.

\section{Список литературы / References}

[1] Левшин Е.А., Артюх С.Н., Тосенко В.М. Тенденции развития зарубежного высокоточного оружия с полуактивными лазерными головками самонаведения, Известия РАРАН, приложение 2009, 3, 117-121 [Levshin E.A., Artyukh S.N., Tosenko V.M. Development trends of foreign high-precision weapons with semi-active laser homing heads, Izvestia RARAN, Supplement 2009, 3, 117-121 (in Russian)].

[2] Семенов С.С., Щербинин В.В. Оиенка технического уровня систем наведения управляемых авиационных бомб. М.: Машиностроение, 2015. 326 с. [Semenov S.S., Shcherbinin V.V. Assessment of the technical level of guidance systems for guided bombs. Moscow: Mashinostroenie, 2015. 326 p. (in Russian)].

[3] Ласточкин Ю.И., Козирацкий Ю.Л., Донсков Ю.Е., Морареску А.Л. Боевое применение войск радиоэлектронной борьбы как составная часть оперативного искусства объединения сухопутных войск, Военная мысль, 2017, (9), 18-25 [Lastochkin Yu.I., Koziratskiy Yu.L., Donskov Yu.E., Moraresku A.L. Combat use of electronic warfare troops as an integral part of the operational art of uniting the Ground Forces, Military Thought, 2017, (9), 18-25 (in Russian)].

[4] Козирацкий Ю.Л., Юхно П.М. Синтез оптических помех, Радиотехника, 2000, (8), 4-11 [Koziratskiy Yu.L., Yukhno P.M. Synthesis of optical interference, Radio engineering, 2000, (8), 4-11 (in Russian)].

[5] Донсков Ю.Е., Татарчуков В.А., Загорудько А.В. Защита тактических формирований в операции: методический аспект, Военная мылсль, 2006, (4), 42-46 [Donskov Yu.E., Tatarchukov V.A., Zagorudko A.V. Defense of tactical formations in an operation: a methodological aspect, Military Thought, 2006, (4), 42-46 (in Russian)].

[6] Калинков А.К., Юхно П.М. Контроль эффективности помех по траекторным признакам, Радиосистемы (журнал в журнале), 2002, (11), 27-30 [Kalinkov A.K., Yukhno P.M. Monitoring the effectiveness of interference by trajectory signs, Radio systems (journal in journal), 2002, (11), 27-30 (in Russian)].

$$
-869-
$$


[7] Юхно П.М. Преднамеренные оптические помехи высокоточному оружию. М.: Радиотехника, 2017. 640 c. [Yukhno P.M. Intentional optical interference with precision weapons. Moscow: Radio engineering, 2017. 640 p. (in Russian)].

[8] Левшин Е.А., Рыжов А.В., Огреб С.М. Оценка характеристик рассеяния лазерного излучения полидисперсной системой аэрозольных частиц методом Монте-Карло, Вестник Воронежского государственного технического университета, 2008, 4(4), $73-77$ [Levshin E.A., Ryzhov A.V., Ogreb S.M. Estimation of the characteristics of laser radiation scattering by a polydisperse system of aerosol particles by the Monte Carlo method, Bulletin of the Voronezh State Technical University, 2008, 4(4), 73-77 (in Russian)].

[9] Артюх С.Н., Левшин Е.А., Рехвиашвили В.Н. Стенды полунатурного моделирования для проведения экспериментальных исследований эффективности воздействия помех на оптико-электронные системы наведения управляемого оружия, Вестник Воронежского государственного технического университета, 2011, 7(1), 25-29 [Artyukh S.N., Levshin E.A., Rekhviashvili V.N. Stands for semi-natural modeling for experimental studies of the effectiveness of interference effects on optoelectronic guidance systems of guided weapons, Bulletin of the Voronezh State Technical University, 2011, 7(1), 25-29 (in Russian)].

[10] Патент № 2645046, МПК F42B 15/01 (2006.01) Полуактивная головка самонаведения. Е.А. Левшин, В.Н. Рехвиашвили, В.В. Беляев, Т.М. Хакимов, М.Л. Паринов, С.Е. Балаин - заявлено 24.10.2016; опуб. 15.02.2018, Бюл. № 5 [No. 2645046 E.A. Levshin, V.N. Rekhviashvili, V.V. Belyaev, T.M. Khakimov, M.L. Parinov, S.E. Balain Semi-active seeker (Moscow: Rospatent) (in Russian)].

[11] Донсков Ю.Е., Татарчуков В.А., Загорудько А.В. О способах боевого применения комплекса групповой защиты в общевойсковом бою, Военная мысль, 2006, (11), 43-46 [Donskov Yu.E., Tatarchukov V.A., Zagorudko A.V. On the methods of combat use of the group protection complex in combined arms combat, Military Thought, 2006, (11), 43-46 (in Russian)].

[12] Левшин Е.А., Артюх С.Н., Непомилуев А.Ю. Предложения по защите объектов бронетанкового вооружения и техники от управляемых ракет с активными лазерными головками самонаведения, Известия РАРАН, приложение 2013, 3, 224-228 [Levshin E.A., Artyukh S.N., Nepomiluev A.Yu. Proposals for the protection of objects of armored weapons and equipment from guided missiles with active laser homing heads, Izvestia RARAN, Supplement 2013, 3, 224-228 (in Russian)]. 